\title{
Enlightenment of Safety Life Cycle Theory In Risk Management of Chemical Industry Park
}

\author{
Xinjie Xu \\ SaiFeiTe Engineering Group CO.LTD \\ Qingdao, China \\ xuxinjie@sft360.com
}

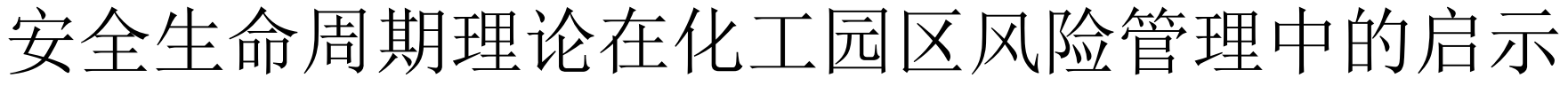

徐新杰

\author{
赛飞特工程技术集团有限公司 \\ 青岛 266100, 中国 \\ xuxinjie@sft360.com
}

\begin{abstract}
The construction of chemical industry park is the overall trend of the development of domestic and international chemical industry in recent years, and it is an important mode for modern chemical industry to develop circular economy and promote the transformation and upgrading of industrial structure.This paper combined with the actual situation of chemical industry park, risk management, this paper USES the integral definition of safety lifecycle theory from the park, the early stage of the risk analysis, the overall security needs, risk control requirements, the implementation of risk control, such as to improve the risk control mechanism of the park at various stages of risk management were analyzed, and on the risk management, the problems in the analysis summary, strengthen the risk management countermeasures and Suggestions are put forward.
\end{abstract}

Keywords-functional safety, risk, managementt

摘要一化工园区的建设是近年来国内国际化工产业发展的 整体趋势, 是现代化学工业发展循环经济、推动产业结构转型 升级的重要模式。本文结合化工园区风险管理的实际情况, 采 用安全生命周期理论从园区的整体定义、前期风险分析、整体 安全需求、风险管控的要求、风险管控的实现、风险管控机制 的改进等园区风险管理的各个阶段进行分析, 针对园区风险管 理中存在的问题, 进行分析总结, 提出加强园区风险管理的对 策和建议。

关键词一功能安全, 风险, 管理

\section{I. 引言}

20 世纪 40 年代初, 起源于美国的化工园区因其集中 模式发展石油化学工业, 逐步带动了一大批石油化学工 业聚集区, 开创了世界化工园区大规模建设发展的雏形
和先河。二战结束后, 其他国家借鉴美国模式, 大力发展 的化工园区模式, 带动了战后经济的复苏和发展 ${ }^{[1]}$ 。我国 化工园区起步较晚, 最早的一批化工园区于 20 世纪 90 年代末在长三角地区兴起。伴随着改革开放的不断深入 和经济的迅猛发展, 化工园区建设也已步入快速发展通 道。

化工园区模式作为一种能源循环利用、规模经济效 益好的发展形式, 因化工企业的高度聚集造成风险倍增, 自建立以来, 一直受到社会各界的广泛关注。如何对化 工园区进行有效的风险管理? 现阶段的研究焦点主要针 对事故预防的安全监管、事故发生过程的应急救援 (以应 急装备布置和应急管理为核心)、化工园区的安全规划等。 本文提出的园区应用安全生命周期理论进行风险管理, 基本涵盖以上三方面。尤其以安全规划为主要着力点。安 全规划关系到化工园区本质安全问题, 对于研究危险设 施和土地利用的安全规划对于预防事故发生、减缓事故 后果具有极其重要的现实意义。[2]化工园区安全规划技术 和方法的应用, 可以为化工企业和化工园区的发展打下 良好的基础。

\section{II. 安全生命周期理论}

狭义的安全生命周期理论特指安全仪表系统的生命 周期, 由 IEC61508 和 IEC61511 (国内对应为 GB/T20438 和 GB/T21109) 所定义。安全仪表系统的生命周期大致可 以分为工艺设计、危险学习及评估、安全功能分配、系统 设计、系统集成、现场安装、调试和验证、系统投运及维 护、系统升级或更新换代等阶段 ${ }^{[3,4]}$ 。每个化工园区都应 该有自己的风险管理系统, 而园区的风险管理系统与装 置的安全仪表系统在实现功能安全的机制上是一样的, 都是为了对可能发生的危险采取紧急措施, 并对继续恶 
化的状态进行及时响应, 使其进入一个预定的安全情况, 从而使危险和损失降到最低程度, 保证财产、环境和人员 安全 ${ }^{[5]}$ 。

化工园区风险管理系统的安全生命周期可以分为园 区安全设计规划、园区风险评估、园区风险管理系统建设、 安全监管、管理系统的升级换代等五个阶段。化工园区的 管理者 (如管委会等) 必须根据行业的发展形势、园区的 自身特点运用安全生命周期理论做好对风险管理系统的 升级或更新换代。

\section{III. 化工园区风险管理系统的安全生命周期}

化工园区作为一个完整、复杂的系统，由诸多的园区 企业组成。园区企业安全生产管理上的自主管理, 很大程 度上影响了园区的风险管理, 园区的管理者很容易变成 针对单个企业的监管者, 而忽视对整个园区风险管理系 统的建立和管理。参照安全生命周期理论, 园区的风险管 理系统主要分为以下五个阶段:

\section{第一阶段：园区安全设计规划}

园区的安全设计规划是化工园区风险管理系统的基 础。作为最底层的基石园区安全设计规划必须从自身的 定位、园区的发展、风险的控制等多个方面统筹规划。安 全设计一般是针对现状安全水平与安全目标间的差距, 找出具体的危险源, 积极采取控制措施, 以消除危险源或 减少危险源的危险性, 或调整土地利用性质, 整治各个规 划对象。在事故发生前, 降低事故的发生概率; 在事故发 生后, 控制事故的蔓延扩大, 将损失减少到最低限度, 从 而达到降低风险及预期损失, 实现规划安全目标的目的。

进行化工园区安全规划遵循以下原则: (1)预防性: “防 患于未然” 是危险设施综合整治措施的根本目的。在灾害 发生之前, 予以杜绝或防范, 减少其带来的危害和损失。 同时, 对于现存的安全隐患, 要积极整改。因此, “预防 为主、防治结合” 是危险设施风险控制措施的重要原则; (2)系统性: 危险设施土地利用安全规划本身是一项系统 工程, 是以系统论方法为指导的。规划的各步骤存在着内 在联系, 并相互依托。危险设施综合整治措施的提出是对 风险评价结果综合分析的产物, 是以风险评价为前提和 基础的; (3)可行性: 危险设施综合整治措施要基于城市的 自然环境条件和现有的经济、技术水平, 并且不能与现行 的国家和地方的法律、法规相抵触。同时, 鉴于城市公众 不同的文化、宗教等背景, 在危险设施综合整治措施具备 经济、技术可行性的同时, 还要考虑公众的心理承受能力。

缺乏科学的安全规划是化工事故造成严重后果的根 本原因, 有些化工园区存在易燃易爆车间与相邻企业靠 近、企业厂房靠厂房、厂房与生活用房和职工宿舍相连
等防火间距不足的现象, 既容易引发火灾爆炸事故, 又 不符合相关安全法规要求, 一旦发生事故, 很可能造成 连锁反应, 对相邻危险源产生影响, 进而产生次生、衍 生事故, 导致群死群伤的灾难性后果 ${ }^{[6]}$, 因此在国务院 办公厅印发的《安全生产“十一五”规划》中, 提出了“要 开展化学工业园区区域风险评价和安全规划”,[7]。

\section{第二阶段：园区风险评估}

当前的园区风险评估是对园区危险源、应急管理等方 面的逐项评价分析, 未对园区的风险管控体系的进行 整体系统有效的评估。引入功能安全分析中的保护层 分析 (LOPA) 方法法建立园区保护层模型, 根据具体 危险源对功能安全的不同要求, 以保护层模型的方式 对安全功能进行有效分配, 共同实现对整个园区风险 的有效管控, 将是以后园区风险评估的主流方法。

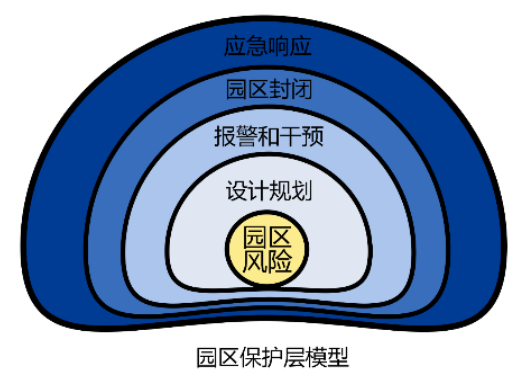

图 1 园区保护层模型图

\section{第三阶段：园区风险管理系统建设}

首先, 要严把项目准入门槛, 保证入园企业质量。 一些地方片面追求经济发展, 见项目就上, 结果造成园 区内企业安全情况差别巨大, 安全环境参差不齐, 有的 企业甚至一味追求经济效益, 对安全管理置若罔闻, 从 起步开始就埋下了安全隐患, 造成不可预计的风险。所 以必须要加强源头管理, 从项目立项审批开始。根据国 家产业政策和行业发展方向, 适合园区整体安全规划, 产业规划, 坚决拒绝国家淘汰落后产能的项目入园。对 拟入驻的企业要严格篮选, 科学划分, 取舍有度, 严禁 不符合园区发展方向的企业入驻。强化法制意识, 落实 安全生产责任主体。企业是安全生产的责任主体, 而企 业法人是安全生产的第一责任人。俗话讲"安全工作老 大难, 老大一抓就不难"。

第二, 要建立专门的园区安全管理机构, 安全监管 要有人。根据国务院安委会办公室关于进一步加强化工 园区安全管理的指导意见》（安委办（2012）37号）第 六条的要求: 园区安全生产管理机构应当配备满足园区 安全管理需要的人员, 其中要有一定数量的具有化工安 
全生产实践经验的人员。专业化的人才队伍是保障监管 有效进行的前提。

第三，要用科学的管理手段。化工园区针对涉及 “两重点一重大”（重点监管的危险化工工艺、重点监管 的危险化学品和重大危险源）的安全管理, 建立风险分 级管控和隐患排查制度，应设专门的信息管理档案，并 随着项目的进驻、建设，及时更新完善。

最后，建设应急救援系统。包括建立应急救援指挥 平台, 建立园区应急资源数据库; 建立应急预案管理系 统，做好线上线下演练; 建立应急监测监控预警联动系 统，及时向周边社区发布危险性告知和预警信息; 建立 应急救援物资储备管理系统，加强物资溯源管理；建立 应急综合分析和调度指挥决策系统等。

\section{第四阶段：安全监管}

实践是检验真理的唯一标准,当风险管理制度已经 建立, 从设计、人员到制度、应急都已经建立之后，怎 样让系统有效的运转就是最后的实践环节。

现阶段安全监管工作存在的问题有: 1、执法人员 大多不是专业出身, 缺乏对安全生产相关法律法规的系 统学习, 在执法工作中凭经验机械片面地理解适用法律 法规的条款，对有些违法行为的定性把握不准，在行政 执法过程中难免出现误差；2、对有关法律法规宣传、 普及力度不够; 3、个别企业只要权利不要义务, 只顾 个人利益, 没有全局观念, 给安监工作造成了很多被 动。

相关部门应选拔专业对口的优秀人才到安监岗位, 继续加大法律法规宣传力度，提高企业素质，增强风险 管理的效能。

\section{第五阶段：管理系统的升级换代}

任何系统都不是一成不变的, 都需要根据时代的变 化、理论的进步衍化出符合当下实际情况的风险管理系 统。

\section{IV. 结论}

园区风险管理系统目前在国内外都处于一个发展阶 段。园区风险管理应运用安全生命周期理论, 在整体定 量风险评估的基础上, 采用保护层的理论, 对园区规划中 的企业各危险源、脆弱目标间的综合影响和园区安全容 量等进行科学分析, 为政府相关决策部门提供指导和参 考。
参考文献

[1] 朱和, “世界化工园区的百年之路”, 中国石油石化, 2006,9:24 25.

[2] 张宏博, “化工园区的安全管理”, 中国化工贸易,2018 年第 03 期

[3] IEC61508, Functional Safety of Electrical/Electronic/Pro-grammable Electronic Safety-Related Systems, InternationalElectrotechnicalComm ission[S].

[4] IEC61511, Functional Safety of Electrical/Electronic/Pro-grammable Electronic Safety-Related Systems, InternationalElectrotechnicalComm ission[S].

[5] 黄文君, “安全仪表系统的功能安全设计”, 自动化仪表, 第 31 卷 第 7 期 2010 年 7 月

[6] 徐超, “论企业安全生产管理中存在的问题与改进措施”, 现代经 济信息 2012（67-70）

[7] 吴宗之, “化工园区土地利用安全规划优化方法”, 化工学报, 2011 $62(45-50)$ 